\section{Daniel Alcides Carrión: una visión funcional}

\author{
Daniel Alcides Carrión: \\ a functional view
}

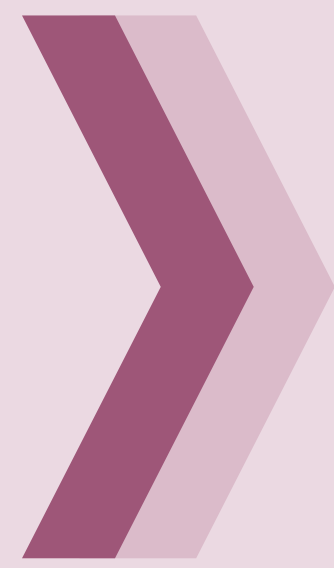

José Alejandro Graña-Aramburú ${ }^{1}$

1 Médico ginecólogo. American Board Certified.

Magíster en Historia, Universidad Nacional Mayor de San Marcos. Doctorando en Medicina, UNMSM.

Miembro de la Asociación de la Historia de la Medicina y Parques Conmemorativos y de la Asociación Médica Peruana Daniel Alcides Carrión.

Docente de Historia de la Medicina y Filosofía, Universidad Privada San Juan Bautista, sede Chorrillos.

\title{
RESUMEN
}

Se hace la consideración de Daniel Alcides Carrión, héroe de la Medicina peruana y de la Nación, desde el punto de vista fenomenológico, tanto filosófico como psicológico, considerando más la visión social que un fenómeno individual, bajo las influencias de las corrientes de pensamiento vigentes a fines del siglo $X I X$. Tanto el romanticismo como el positivismo fueron de origen europeo, pero influenciaron definitivamente en el Perú en la época de Carrión y, seguramente, tuvieron que ver en gran medida con su decisión a la autoexperimentación. Se hace especial mención a su rol pionero como investigador clínico y se remarca la necesidad de completar aquellos acontecimientos que formaron parte del funcionamiento del héroe en el tiempo histórico correspondiente.

Palabras clave: Daniel Alcides Carrión; autoexperimentación; autoinoculación; héroe; medicina; nación; Perú; psicología; filosofía; visión

\section{INTRODUCCIÓN}

La autoexperimentación del joven estudiante de Medicina Daniel Alcides Carrión, en agosto de 1885, al hacerse inocular los raspados de una lesión de verruga peruana, que le causó la muerte, ha sido vista desde diversos puntos, la mayoría de apreciación histórica, aunque en general existen pocos fundamentos al respecto

para evaluar sus motivaciones y su significado intrínseco. Se ha intentado evaluar la acción de la autoinoculación misma desde diferentes ángulos, que podrían incluir hechos tales como: una conducta precipitada, ${ }^{1-3}$ un acto irresponsable y hasta suicida, una búsqueda de estatus en la élite médica, ${ }^{1}$ la investigación científica pura y desinteresada (diario de Carrión) y, finalmente, la 
actitud heroica, que, de hecho, es la más aceptada entre los médicos. ${ }^{4}$ Sin embargo, cabe considerar también los hechos circunstanciales que rodearon ese accionar, y que pudieron tener peso en la actitud y en las motivaciones de Carrión, tales como las contingencias dramáticas por las que atravesaba el país después de la ocupación chilena, en especial el empobrecimiento de la enseñanza médica y la carencia casi total de implementos para llevar a cabo una experimentación en regla, según el modelo científico europeo. ${ }^{5-7}$ Además, la evolución misma del siglo XIX aportó diferentes corrientes de pensamiento que, de seguro, tuvieron influencia de una u otra forma en los médicos y estudiantes de la época, ${ }^{8,9}$ aunque tal vez Carrión no fuera absolutamente consciente de las mismas.

\section{CONSIDERACIONES TEÓRICAS}

Resulta ya indiscutible en el Perú la consideración de Carrión como héroe, teniendo en cuenta la vasta literatura existente al respecto que lo cataloga como tal, en especial aquella escrita por médicos, ${ }^{2-4,10-14}$ y que califica su autoinoculación y su comportamiento durante el desarrollo de su enfermedad como un «acto de inmolación» 0 como un «sacrificio» en pro de la Medicina. Por otro lado, la incansable labor de varios médicos historiadores, como el de Gustavo Delgado Matallana, oficializan el comportamiento heroico de Carrión, que concluye en su reconocimiento como héroe nacional por la Ley $\mathrm{N}^{\circ} 25342$ del Congreso de la Nación, el 7 de octubre de 1991, durante el primer gobierno del presidente Fujimori.

Según la historiadora Carlota Casalino, ${ }^{15}$ la proporción de héroes nacionales civiles es escasa en comparación con la de los militares, aproximadamente 607 sobre un total de unos 26 ya oficializados por la Nación, lo que haría más excepcional aun la posición de Carrión en su doble investidura de héroe médico y héroe nacional civil. No obstante, debe tenerse en cuenta que la condición de héroe es una construcción cultural, que contribuye al simbolismo nacional y, generalmente, político de un estado-nación, entre personas que comparten una misma historia y un mismo territorio. ${ }^{15}$ Es decir, el estatus heroico resulta ser una idea grupal compartida $y$, al mismo tiempo, concedida a un individuo cuyas determinadas acciones de entrega le merecen un simbolismo de excelencia y también de representación extraordinaria de una comunidad 0 una nación. El héroe no es tal en sí mismo, sino que debe forzosamente ser considerado un individuo heroico «desde afuera», por una unión o asamblea de individuos que comparten la misma idea, y que acaba constituyendo un símbolo y que tal vez conlleve, a la larga, hacia algunos elementos míticos.

\section{EL "FENÓMENO CARRIÓN"}

La "fenomenología" es la observación subjetiva que se tiene de un hecho o acontecimiento. Se usa en el enfoque de la filosofía y la psicología. Tanto Husserl como Martín Heidegger ${ }^{16}$ estudian los hechos desde el punto de vista del investigador, como "apariencias" o "evidencias" mentales percibidas por el sujeto, pero que deben ser confrontadas racionalmente para tomar significado. Por su parte, Schütz enfoca la fenomenología en su forma social, refiriendo que los eventos sociales no son captados en forma completa de una sola vez por el individuo que los observa, sino solo parcialmente, de tal manera que la observación resulta ser una situación incompleta y cambiante.

Cada vez se van agregando nuevas configuraciones al constructo de la observación original y el observador también va modificando su apreciación al respecto. Observar un fenómeno sería entonces un hecho subjetivo, pero que no se limitaría a una sola observación sino a varias, y siempre se pueden sumar nuevas apreciaciones. Cabría, entonces, desde esta posición, ubicar la acción de Daniel Alcides Carrión como un «fenómeno», no únicamente individual, sino más bien social o grupal, sujeto a diversas observaciones y ángulos parciales de diferentes observadores.

Buscar la verdad sobre la autoexperimentación de Carrión y sus significados requiere, por tanto, diversas consideraciones sobre el hecho mismo y sobre su dilucidación. Se trataría de un fenómeno complejo que requiere apreciar sus componentes históricos desde diversos parámetros y por diferentes investigadores, que eventualmente puedan llegar a un consenso. Para esto, habría también que tener en cuenta las contingencias características del Perú a finales del siglo XIX, así 
como las corrientes de pensamiento europeas que estuvieron vigentes en la época e influenciaron con más o menos fuerza en el país. En el presente trabajo enfocamos el "fenómeno Carrión" inmerso tanto en el pensamiento romántico como en el del positivismo científico, predominante en ese siglo.

Durante el siglo XIX tuvo mucha influencia una corriente de actitud existencial, de particular comportamiento, denominada Romanticismo; más tarde apareció otra visión, de carácter estricto y científico, el Positivismo. Ambas coincidieron en el momento histórico de Carrión. Una de las consecuencias de estas corrientes fue el desarrollo, a partir de mediados del siglo y más concretamente hacia finales del mismo, de la denominada "teoría del germen', que cambió totalmente la dirección de la investigación científica y absorbió el pensamiento médico de entonces. Se trató, por tanto, de un momento histórico de cambios radicales que iniciaron una nueva era científica y médica.

\section{EL ROMANTICISMO}

Surgió como una respuesta al Racionalismo extremo del siglo XVIII y dio especial importancia y confiabilidad a los sentimientos humanos, en especial al Yo (que reside en el interior de las personas), considerándolo como una cualidad suprema, ${ }^{8}$ cuyos designios y apreciaciones se consideraron superiores a los objetos de la realidad externa. Fue una forma de entender la vida basada en una sobrevaloración del Yo personal, inclusive en busca de lo infinito y eterno. ${ }^{8}$ Pero esta imposibilidad de extrapolar o superar los acontecimientos de la realidad concreta llevó con frecuencia a los románticos hacia un sentimiento de frustración en su comportamiento en la esfera de la vida práctica, o a una situación de emociones exaltadas, no haciendo predecible su comportamiento.

En el caso de los médicos "contagiados" con el Romanticismo, destacaron los sentimientos de extrema dedicación, el sacrificio, la abnegación absoluta, la idea del servicio desinteresado ${ }^{17} y$, en especial, la visión pura de la Medicina como un acto supremo en pro de la humanidad. Hay varios ejemplos de sacrificio y autoexperimentación realizados por investigadores europeos, como el doctor Strauss, que pereció víctima de una inocu- lación voluntaria del cólera, y otros más, que autoexperimentaron con pústulas o mosquitos infectados por la fiebre amarilla., ${ }^{1,2}$ En 1987, Daniel Zagury practicó una autoinoculación con elementos moleculares (genoma) del $\mathrm{VIH}$, cuyas consecuencias eran impredecibles. ${ }^{1}$ Todos estos casos están vinculados con la sobrevaloración del Yo emocional.

En total, según Altman, ${ }^{3}$ en los últimos cuatro siglos al menos 185 investigadores han participado como sujetos de experimentación en 137 experimentos, incluyendo la autoinoculación. Las motivaciones para estos actos pueden resumirse con relativa confiabilidad así: la conveniencia, que lo exime del consentimiento; la confiabilidad, que asegura el cumplimiento; curiosidad irresistible y algunas otras actitudes, de las cuales, por supuesto, la más importante es el hecho moral de que si el sujeto está en verdad dispuesto a someterse al experimento. Tal hecho justificaría el procedimiento mismo ${ }^{3}$ y tendría un alto valor moral. Así pues, ni la autoinoculación ni el heroísmo consecuente pueden estar desprovistos del componente ético-moral, que forma parte absoluta de la experimentación propia.

Dado que el Romanticismo llegó a Perú alrededor de $1840^{18}$ e influenció decididamente el comportamiento de la sociedad burguesa de entonces, es concebible que un joven estudiante como Daniel Alcides Carrión haya poseído una naturaleza extremadamente romántica sobre su rol médico y sobre un deseo especial de investigador médico, que motivó, en última instancia, su imparable decisión de autoexperimentar. Esto tuvo que haber requerido el convencimiento absoluto de que la autoexperimentación era el camino indicado en su investigación, por encima de las circunstancias concretas, como el peligro involucrado en el acto mismo. Sobre todo, tuvo que haber una entrega, probablemente de sentimiento patrio y frustración científica, dada la postración lamentable de la Medicina en la posguerra y la casi carencia total de elementos disponibles para la investigación científica. ${ }^{2,19}$ Además, debió requerir también de un sentimiento de responsabilidad personal que terminara convirtiendo su propia persona en un elemento experimental confiable con poder de observación "desde dentro". 
A juzgar por las cartas escritas a su familia, entre 1877 y $1885,{ }^{14}$ usando lenguaje sencillo y hasta imperfecto, se entiende que Carrión poseía, al menos, una gran ansia de comunicación con sus seres queridos bajo una importante vinculación emocional, lo que sugiere una gran sensibilidad de su Yo personal: A doña Dolores, le escribió: “Deseo que su santo lo pase usted bien el año entrante, sea que vaya ahora sea que no vaya yo, tendré el placer de estrecharla entre mis brazos". Y más tarde, a su padrastro don Alejo, a raíz del fallecimiento de la madre de este: "Conformidad, querido papacito, por su salud, por sus hijos y demás familia; conformarse con aquel acápite de la Santa Biblia que dice: "Si de Dios recibimos los bienes, ¿por qué no hemos de recibir los males?"». Y nuevamente a su madre: "Mi jamás olvidada mamá". A lo que doña Dolores responde: "Mi querido y no olvidado hijito de mi corazón". Esta idiomática emocional, aunque común entre seres queridos, es de alguna manera un rezago del Romanticismo y revela, al menos, el aspecto de amor familiar en alta estima, sentimiento que podría ser extrapolado en un momento dado hacia cualquier situación, inclusive la de la autoexperimentación.

La famosa Belle Époque, que formó parte de la corriente romántica, transcurrió entre 1871 y el comienzo de la Primera Guerra Mundial, en 1914, en especial en Francia y Bélgica. Se caracterizó por un sentimiento de general optimismo, estabilidad económica y paz. Se dio oportunidad para que florecieran las artes y la ciencia. Justo por entonces, apareció la "teoría del germen", impulsada en gran parte por la dedicación y sacrificio de los científicos que hicieron los descubrimientos pertinentes sobre los microbios, como los de Koch, que demostraron sus postulados e iniciaron la era auténtica de la investigación. Los ecos de la Belle Époque llegaron a Perú, sobre todo con la inmigración de hombres de negocios europeos, sobre todo hacia Arequipa, quienes finalmente, se esposaron con damas de la sociedad. Algunos de estos inmigrantes se contrajeron nupcias con damas de familias de la oligarquía peruana, ${ }^{20}$ algunas de las cuales habían alcanzado tal estatus debido a la riqueza generado por el guano a mediados del siglo. ${ }^{21}$

Sin embargo, es probable que la era de la bacteriología se iniciara en 1889 , con la llegada del primer microscopio traído de Europa por el doctor Ricardo Flores. ${ }^{18}$ Pero Carrión ya había dado comienzo a la etapa de la investigación clínica mediante la autoexperimentación y recolección de datos de sus historias clínicas y su diario, antecediendo en alguna forma a la era bacteriológica científica. Es posible que las influencias netas de la Belle Époque se manifestaran algo más tarde en Perú, a comienzos del siglo XX, a semejanza de lo que refiere Luis Alberto Sánchez sobre Abraham Valdelomar, en el caso de la literatura. ${ }^{22}$ No obstante, entre los eventos sociales de la Belle Époque surgieron con fuerza las élites, ${ }^{23}$ que diferenciaron a las clases sociales dominantes de las populares, de tal manera que los movimientos intelectuales, la ciencia y la Medicina transcurrieron, en gran medida, como parte de estos movimientos, personificados en agrupaciones y academias exclusivistas. Esto originó un extenso trabajo científico, como la creación de textos en Europa, que articulaban la anatomía patológica con la bacteriología. Un ejemplo de esto es el Tratado de patología general, del profesor Follin en Francia. ${ }^{24}$

Tal vez valga la pena recordar que el entendimiento del "heroísmo" tiene correspondencia con la concepción romántica. Más lejanamente, pertenece al grupo de valores generados por el Humanismo europeo; concretamente, tiene que ver con aquellos valores vinculados con el prestigio, poder y gloria. Representa la exaltación de la excelencia y la admiración hacia el individuo, que a los ojos de la sociedad realiza un comportamiento extraordinario y de gran significado. Este sentimiento también se dio en el Perú y apareció en la literatura contemporánea del siglo, como en Los muertos que viven, relacionado con la obra de Casimiro Ulloa. ${ }^{25}$ Curiosamente, la actitud heroica no se ajusta del todo a la doctrina cristiana pura y a la idea de "fraternidad", pues la admiración excesiva puede confundirse con una ideología extrema y hasta idolátrica.

Es curioso, no obstante, que pese a las influencias románticas, que de hecho existieron en la vida de Carrión, no se conocen por parte de él relaciones amorosas, más allá de sus vínculos familiares, pese a que según algunos autores ${ }^{3}$ ya había superado su normal complejo de Edipo y podía volcar su pasión 
hacia cualquier mujer. Al parecer, su interés y sus sueños fueron solo por el estudio y el descubrimiento científico, que finalmente se cristalizaron en la actitud irreversible de su autoinoculación, para lo cual era necesario que Carrión profesara una total honestidad consigo mismo, libre de elementos neuróticos y de complejos. ${ }^{3}$

\section{LA VISIÓN CIENTÍFICA DEL POSITIVISMO}

Según señala Auguste Comte, fundador del Positivismo clásico en la década de 1840 , todo el desarrollo de la sociedad humana depende en última instancia del desarrollo científico. ${ }^{9} \mathrm{La}$ historia de la ciencia es el núcleo de la historia general de la especie humana. Toda sociedad y toda ciencia deben, necesariamente, atravesar por tres estadios o etapas de conocimiento: la teológica, la metafísica y, finalmente, la etapa positiva. En esta última, las ciencias deben concentrarse en la descripción de los fenómenos y buscar sus leyes. Es decir, la verdad depende de la metodología científica y la posibilidad de que los fenómenos sean demostrables, medibles y verificables. Por tanto, el Positivismo descarta toda posibilidad filosófica o metafísica en la búsqueda de la verdad o de interpretación de la realidad natural.

Una idea íntimamente ligada al Positivismo es la del "progreso": encontrar leyes relacionadas con los fenómenos naturales, llegar a predicciones que permitan descifrar la naturaleza y los logros tecnológicos, base de todo el progreso humano. ${ }^{9}$ El «progreso», pues, desde el punto de vista de la finalidad práctica del Positivismo, constituye el verdadero meollo del desarrollo social y su avance definitivo.

Salazar Bondy señala que el Positivismo llegó a Perú aproximadamente en 1860 , pero cobró verdadera importancia una década más tarde, influenciando todos los niveles culturales del país. Así, el gran escritor y crítico de la sociedad limeña Manuel González Prada afirmaba que toda la realidad podía reducirse a los hechos concretos; el rector de la Universidad Nacional Mayor de San Marcos Javier Prado Ugarteche creía con firmeza en una suerte de darwinismo social, que afirmaba las diferencias psicológicas e intelectuales entre los diversos grupos humanos que conformaban la sociedad peruana, en especial en lo referente a los indios y negros, a quienes ella miraba peyorativamente. $^{6}$

Desde la perspectiva del ambiente médico, la figura más representativa del Positivismo en Perú fue el doctor Celso Bambarén, destacado profesor de la Facultad de Medicina de San Fernando y político notable. ${ }^{26}$ Al parecer, se afianzó a las ideas evolutivas de Darwin y Spencer, bajo una creencia científica absoluta. Se rumoreaba que las enseñaba a sus alumnos de Anatomía. Esto le costó una enemistad con el arzobispo Goyeneche y con diversos sectores de la sociedad de Lima. También fue uno de los pioneros de la investigación, pues estudió con gran dedicación científica la función de las válvulas del corazón, anticipándose en esto inclusive a los científicos extranjeros. ${ }^{26}$

Es seguro que los miembros fundadores de la Academia Libre de Medicina de Lima, que llamaron al concurso sobre la verruga peruana, que entusiasmó a Carrión, estaban fuertemente influenciados por la idea del progreso médico al estilo europeo. Por eso, la Academia tuvo un cierto sentido exclusivista y elitista y fue como una suerte de club que pretendía manejar los aspectos científicos de la Medicina en el país y también los aspectos políticos, tales como la salud pública o "Medicina pública", como se llamaba entonces. ${ }^{27,28}$ En este sentido, el concurso sobre la verruga pudo cumplir teóricamente con ambos aspectos, aunque tal concurso era casi imposible de cumplirse en la práctica, por la falta de recursos económicos $y$, en especial, por la ausencia de implementos y facilidades, como la disponibilidad de verdaderos laboratorios médicos.,19

No podemos señalar con certeza hasta qué punto la corriente positivista de entonces influenció en la visión científica y social de Carrión. Sin embargo, es muy probable que la falta de progreso en las ciencias médicas y su estado letárgico en la etapa posterior a la Guerra del Pacífico, haya tenido sobre él un profundo impacto frustrante $y$, al mismo tiempo, un deseo empeñoso de contribuir a cualquier costo con el progreso de la Medicina, hasta llegar a concebir sin más circunstancias la idea radical de la autoexperimentación: "Pase lo que pase, hoy quiero inocularme...". Así, pues, en la autoexperimentación, se involucra un deseo de avance o de progreso, tal como predicaba la visión positivista. 


\section{LA "TEORÍA DEL GERMEN"}

Los avances científicos en el campo médico durante el siglo XIX dieron lugar a una nueva visión de la enfermedad y su etiología, pues hasta ese entonces se consideraba que era provocada por «miasmas» o aires procedentes de lugares sin higiene alguna, alteraciones climáticas 0 deterioros individuales del organismo humano, como la desnutrición. ${ }^{29}$

Las observaciones de Ignaz Semmelweis, sobre la relación del origen de la fiebre puerperal con el examen a las parturientas sin higiene alguna en el hospital de Viena, y su propuesta del lavado de manos con hipoclorito de sodio, fueron los que primero redujeron notablemente la incidencia de la infección. Algo más tarde se dieron los geniales descubrimientos de Pasteur sobre los microbios y su transmisión a los seres vivos y el uso de antisépticos en las heridas por el cirujano Lister, factores que revolucionaron definitivamente las ideas antiguas sobre las infecciones y llevaron a la ciencia médica a una auténtica posición de vanguardia. El punto más importante en esta nueva visión lo produce Roberto Koch en 1882, tanto con sus estudios sobre el ántrax como sobre la tuberculosis; aisló al agente causal de este último y reprodujo la enfermedad en animales de laboratorio. Así desarrolló sus teorías científicas. Esto dio lugar al desarrollo de la bacteriología, tanto en Europa como en América. Cobra especial importancia el trabajo de Frederick George Novy, de la Universidad de Michigan, que dio inicio a la Bacteriología en la Medicina norteamericana. ${ }^{30}$

Aunque estos conocimientos llegaron a Perú en algún momento, es posible que la "teoría del germen" se haya desarrollado tarde, posiblemente debido, en parte, a los estragos de la Guerra del Pacífico; además, el primer microscopio clínico recién fue traído de Europa en 1889 por el doctor Ricardo Flores, quien dictó un curso libre de técnica microscópica y bacteriología en San Marcos. ${ }^{18}$ Por tanto, al momento de la autoexperimentación de Carrión, la bacteriología formal todavía era desconocida en el país, y mucho más la microscopía; por ello, era imposible que se llevara a cabo una investigación completa sobre la verruga, considerando su etiología y aspectos de la anatomía patológica, como dictaban las bases del concurso propiciado por la Academia Libre. ${ }^{27}$ La carencia total de implementación de técnicas de laboratorio, como la microscopía, obstaculizaban una investigación como la que se requería; esto quizás explicaría el escaso interés de los médicos y estudiantes por el concurso y, tal vez, influyó en la propia decisión de Carrión para experimentar en su propia persona.

\section{¿CÓMO DEBE RECORDARSE LA FIGURA DE CARRIÓN?}

Con justicia deberíamos ver a Daniel Alcides Carrión como un creador. Su autoexperimento no fue un simple acto personal o heroico, sino que inició la investigación clínica en el Perú y América, que fue posteriormente seguida por tantos otros grandes pioneros de la ciencia médica. ${ }^{5,17,18,31,32}$ Es en este aspecto que Carrión merece el respeto de la profesión y de la conciencia médica, y que él mismo se lo comunica a uno de sus compañeros de estudio: "Aún no he muerto amigo mío, a ustedes os toca terminar la obra ya comenzada, siguiendo el camino que les he trazado".

\section{CONCLUSIONES}

Daniel Alcides Carrión es el héroe de la Medicina peruana y también héroe civil de la Nación, aunque hasta el momento existen aspectos de su historia y de su accionar que permanecen poco explicados. Se hace necesario, por tanto, considerar sus acciones extraordinarias no solamente como un fenómeno aislado, sino como una visión de la sociedad, e incluirlo de lleno en el tiempo histórico correspondiente, es decir, a finales del siglo XIX, en un país postrado por las consecuencias de la guerra y, de alguna manera, influenciado por las corrientes de pensamiento que en ese entonces estaban en su apogeo en Europa: el Romanticismo y el Positivismo científico. Pero puede decirse también que la condición de héroe con la cual se le ha investido, seguramente con toda justicia, corresponde a la visión racional y humanista dentro del etnocentrismo europeo, con un conjunto de valores bajo los cuales el héroe no se califica a sí mismo como tal, sino que el halo con el que se le mira resulta ser una situación concedida, en este caso, por el gremio médico y por la Nación. 


\section{REFERENCIAS BIBLIOGRÁFICAS}

I. García U. Historiografía de la enfermedad de Carrión. Parte I, Folia, Dermatol (Perú). 1998;9(4);47-54.

2. Murillo J, Salaverry O, Mendoza W, Franco C, Calderón W, Rodríguez-Tafur J. Daniel Alcides Carrión y su contribución al imaginario cultural de la medicina peruana. An Fac Med. 2002;63(2):141-59.

3. Perales A. Evaluación ética de la autoexperimentación de Daniel A. Carrión y su perfil de personalidad. An Fac Med. 2003;64(3): 190-8.

4. Delgado-Matallana G. Daniel Alcides Carrión: mártir de la medicina peruana, héroe nacional, Ley 25342. Lima, Perú: Fondo Editorial de la UNMSM; Asociación de Historia de la Medicina Peruana y Parques Conmemorativos; $200 \mathrm{I}$.

5. Odriozola E. La maladie de Carrión ou la verruga peruvienne. París: Carré et Naud; 1898.

6. Portocarrero F. El imperio Prado (1890 - 1970). Lima, Perú: Universidad del Pacifico; 2007.

7. Rosanvallon P. El modelo político francés: la sociedad civil contra el jacobinismo (de 1789 hasta nuestros días). Buenos Argentina: Siglo Veintiuno; 2007. p. I70-I.

8. Jándalo L. Panorámica general del siglo XIX - sociedad y literatura: características del romanticismo [Internet]. Las 9 musas; 2014 [citado 5 jul 20l4]. Disponible en: http://www. las9musas.net/siglol9/romanticismo/caracrom.html

9. Moulines UM. La génesis del positivismo en su contexto científico. Barcelona, España: Universidad de Barcelona, GeoCrítica; 1979.

10. Graña A. Daniel A. Carrión: heroísmo y controversia. Act Med Per. 2007;24(3):245-8.

I I. Lastres J. Historia de la Medicina Peruana. Lima, Perú: UNMSM; I95I.

12. Malpartida-Tello B. El verdadero Daniel A. Carrión. Lima, Perú: Malpartida; $201 \mathrm{I}$.

13. Malpartida B. Cómo salvar un héroe. Lima, Perú:Alfim Pre Prensa Digital; 2014.

14. Peñaloza J, Maguiña C. Daniel A. Carrión: biografía, la enfermedad de Carrión y otras bartonellas. Lima, Perú: Misky; 201 I.

15. Casalino CA. Los héroes patrios y la construcción del estadonación en el Perú (siglos XIX y XX) [tesis para optar el grado académico de doctor]. Lima, Perú: Universidad Nacional Mayor de San Marcos; 2008.

16. Beyer C. Edmund Husserl. En: Zalta EN, editor. Stanford Encyclopedia of Philosophy [Internet]. Stanford, California:The Metaphysics Research Lab; 20I5. Disponible en: http://plato. stanford.edu/entries/husserl/

17 Paz-Soldán CE. Decanos, maestros y médicos de la facultad de medicina de Lima. Lima, Perú: Instituto de Medicina Social, 1957.
18. Velásquez V. Lima a fines del siglo XIX. Lima, Perú: Universidad Ricardo Palma; 2008.

19. Delgado-Matallana G. Evolución histórica de la Facultad de Medicina de San Fernando, Universidad Nacional Mayor de San Marcos. Lima, Perú: Universidad Nacional Mayor de San Marcos, Facultad de Medicina; 2006.

20. Gilbert DL. La oligarquía peruana: historia de tres familias. Lima, Perú: Horizonte; 1982.

21. Klarén PF. Nación y sociedad en la historia del Perú. Lima, Perú: Instituto de Estudios Peruanos; 2004. p. 203-19.

22. Sánchez LA.Valdelomar o la Belle Époque. Lima, Perú: Congreso del Perú; 2009.

23. Cueto M. Excelencia científica en la periferia: actividades científicas e investigación biomédica en el Perú 1890. Lima, Perú: Grupo de Análisis para el Desarrollo (Grade); 1989.

24. Follin E. Traité élémentaire de pathologie externe. París, Francia: Masson; 1879.

25. Ulloa JC. Los muertos que viven. La Reforma Médica. 1916;2(25):76.

26. Bambarén-Alatrista C. Semblanza del Dr. Celso Bambarén Ramírez.An Fac Med. 200 I;62(4):347-54.

27. Ulloa JC, Barrios MC, Pérez-Roca A, editores. Boletín de la Academia Libre de Medicina de Lima. I886; I (I).

28. Paz-Soldán CE. La Academia Libre, 1884-1889. Lima, Perú: Biblioteca de la Reforma Médica; 1936.

29. Fankhauser DB. History of the germ theory of disease. Batavia (Ohio), EE. UU.: University of Cincinnati Clermont College; 2009.

30. Kazanjian PH. The beginnings of bacteriology in american medicine: works of Frederick Novy 1888-1933 [dissertation for the degree of doctor of Philosophy]. Míchigan, EE. UU.: University of Michigan; 2012.

31. Rebagliati R. Verruga peruana (enfermedad de Carrión). Lima, Perú:Torres Aguirre; 1940.

32. Zárate E. Inicios de la escuela de medicina de Lima: Cayetano Heredia el organizador. Lima, Perú: Asamblea Nacional de Rectores; 2005.

\section{Correspondencia}

Dr.Alejandro Graña Aramburú

agrana19@gmail.com

Conflictos de interés

El autor declara no tener conflictos de interés durante el planteamiento, ejecución de la investigación y la elaboración del artículo para su publicación.

Fecha de recepción: 3 de octubre de 2014

Fecha de aceptación: 3 de diciembre de 2014 